\title{
The Timeless Way of Educating Architects: A New Master in "Building Beauty" in Naples, Italy
}

Maggie Moore-Alexander, Centre for Environmental Structure, mm@patternlanguage.com.

Enzo Zecchi, Lepida Scuola, enzo.zecchi@yahoo.it.

Peter Russell, University at Buffalo, prussell@buffalo.edu.

Mariapia Vidoli, University of Strathclyde, maria.vidoli@strath.ac.uk.

Antonio Caperna, International Society of Biourbanism, antonio.caperna@biourbanism.org.

Ombretta Romice, University of Strathclyde, ombretta.r.romice@strath.ac.uk.

Sergio Porta, University of Strathclyde, sergio.porta@strath.ac.uk.

\begin{abstract}
:
Christopher Alexander showed us that beauty can be investigated in nature, in things that are made and built, and in our collective and individual selves, in a way that leads us to understand and enhance wholeness. All of this he pursued on the basis of objective physical evidence. Also, Alexander showed that the unfolding geometry of beauty can be sought with practical means that demonstrate its connections with all of life.
\end{abstract}

A new Master program in "Building Beauty: Experience of Ecologic Design and Construction Process" is now assembling at the University Suor Orsola Benincasa in Naples, Italy, with the mission of pursuing beauty through a new model of architectural education inspired by Alexander, with colleagues of the Center for Environmental Structure (CES), the organization Alexander established for his professional and educational work.

In this paper we introduce the context of "radical" traditions of architectural education and culture from the 1960s and the current debate in the United Kingdom and the US; we then present the program's general vision, that merges a truly holistic practice of building with nature and the community, with a research/evidence based approach to knowledge; finally we focus on pedagogic principles aimed to align with, and support, such vision; the proposed pedagogy covers both teaching and assessment, by introducing a constructionist approach implemented through an original Project-Based Learning model updated with latest fundamentals of Agile Project Management.

Keywords: Architectural education; Christopher Alexander; Agile Project-Based Learning 


\section{Higher Education in Architecture: the need for a paradigm shift.}

\subsection{The problem of architectural education}

Formal higher education in architecture is relatively recent in history. It started around one century ago. Since its very beginning it has been built around a set of values and norms that nobody still today has seriously put in question. The problem with such values is not primarily about professional qualification, or the market. It is about the historical mission of the architect and her/his role in society. Mainstream architecture education has always been about designing extraordinary buildings (or ordinary buildings in unprecedented, extraordinary ways, which means: as if they were extraordinary), being "bold" and unique, "leaving a statement", "thinking out of the box". The professional architect as we know it is a direct product of the age of the avant-gardes, the architect artist and creator whose work is first and foremost an individual interpretation of our time. Like for painters and sculptors, it is the individual and to a good degree mysterious talent of the architect that allows him to challenge the established vision of the world and therefore trigger diversity and ultimately innovation. Innovation and distinctiveness are the goals to pursue.

The fundamental need to "épater la bourgeoisie" is the red wire that linked together the late $19^{\text {th }}$ century Decadents and the early $20^{\text {th }}$ century Cubists, Dadaists and Futurists in all creative arts, including the new architects then sky-rocketing in the mesmeric dizziness of the machine-age ahead. At that point challenging the conventional, being exceptional in the literal sense, that of emerging from the ordinary, became the survival condition for the artist in a world increasingly dominated by the rules of the media system in all its manifestations, from politics to labour, from economics to the new industry of entertainment. As an architect, your success started in those years to be predominantly based on your ability to stand out in the competitive world of image communication before anything else, and architects like all other artists aligned themselves to the rush to exceptionality and amazedness, the "wow" currency of the media age. The problem of such sort of races is that they feed themselves in cycles of increasing inurement, as what impresses one generation very easily becomes routine for the next. After a good century of "shocking the bourgeoisie", the bar is nowadays very close to the limits, and since construction technology pushes the limits quite as restlessly, by no means the circus shows signs of tiredness. Quite on the contrary, the inexorable entropy that levels yesterday's exceptions to today's average makes the profession, and the expectations of the clients, even more aggressively prone to the endless hunger for impressive visuals.

Along this path, because the art of the architects-creators has always been the undisputed link between them and the common good, their responsibility has always been first and foremost towards their Art. But the world has changed. We all usher into a new age of global poverty, environmental challenges and amazing new opportunities. In this new globalized world, it is no longer about the few special buildings, the art-pieces or the top $1 \%$ of the population (Parvin, 2013), nor, in all evidence, can we blindly rely on the naturally progressive nature of large-scale housing industry, the mantra of the inter and post-WWII 
reconstruction period. The battlefield today is the mass of ordinary spaces where global population lives and struggles for life: it is that complex of subtle dynamics in the "space of the ordinary" (Habraken \& Teicher, 2000) that does quite literally constitute "the environment" in the age of urbanization. In this new world, our responsibility as makers can no longer be towards our own Art. It must directly go towards our people, their everyday lives and places, the larger whole we all belong to as living parts and acting peers.

The credit crunch that hit the western world in 2007 only exacerbated a historical crisis that our discipline had already been experiencing for decades (Brolin, 1976; Martin, 1972), triggering the current wave of discussions around a reformation of architecture education. While rarely getting to the fundamentals, such as the identity of the architect in an increasingly unequal globalized world and her/his social mission in the urbanization age, nevertheless such debate has targeted various aspects of the existent system, including the qualification framework (Farrell, 2014; Wright, 2013). The need has been widely reckoned to steer the pathway to the profession towards a more flexible, diverse and interdisciplinary learning environment, responsive to " $21^{\text {st }}$ century skills" (P21, 2002). In this context, the alternative experiences of "radical" architectural education that especially emerged at the end of the 1960s, and have continued to proliferate beside the mainstream, have recently triggered a new wave of interest.

\subsection{The red line of "radical" architectural education.}

In a recent survey conducted in Britain by the Royal Institute of British Architects (RIBA, 2014 ), it was found that $86 \%$ of respondent employers and $82 \%$ of students state that students/graduates lack the knowledge to build what they design; also, $80 \%$ of employers and $73 \%$ of students agree that students lack the practical skills needed to practice architecture.

The "persistent gap" between education and practice is a discord in the profession that has existed since the very beginning of professional architecture education. At the onset, a competition of ideologies between the French École de Beaux Arts and the modernist German Bauhaus models assumed dominance in the schools of architecture, eventually turning what used to be a practical art and an experimental science in the age of the masterbuilders into just a branch of the visual arts in the age of the avant-guards (Wolfe, 1981). Eventually, the prevailing ideology has shown great success in closing the gap (Ockman, 2012).

The general cultural shifts of the 1960s fostered a period in which the social mission of the architect and the statutory position of the discipline underwent considerable reconsideration (Rudolfsky, 1972; Turner, 1977; Turner \& Fichter, 1972), starting a stream of communitarian and collectivist approaches to development based on concepts of self-build, freedom-to-build and right-to-build, still today well represented in both practice and academia (Boano \& Kelling, 2013; Hamdi, 2010; Kroll, 1986; Sanoff, 2000; Trechsel \& Moos, 2003). In the educational area, schools of architecture began to seriously consider several external forces and engage with social and political issues from within their curricula (Boyer \& Mitgang, 1996). Both in the UK and the USA, this led radical pedagogues to foster student-client engagement via the practice of direct construction. The Birmingham School of Architecture, under the leadership of Douglas Jones was reported (unfavourably) by the RIBA to be undertaking "live projects", with a specific emphasis on a 1951 set of row houses designed 
and constructed by students. By the 1960s, direct construction had been integrated into architecture education at UC Berkley under the direction of Christopher Alexander (Carpenter, 1997). In 1967 Progressive Architecture reported on the work of the Yale School of Architecture under the leadership of Charles Moore, with emphasis on "direct involvement of students in real world problems"; this emphasis evolved into the creation of the "first year building project" which has continued more or less uninterrupted since 1967 (Hayes, 2007).

As much as the 1960/70s exceptional wave of "progressive" alternative pedagogies (specifically in architecture but in education as well) were soon largely marginalized in the subsequent decades (Colomina, Choi, Galan, \& Meister, 2012), we recently witness an emergence of design-build programs in architecture education, growing in the United States accredited programs of architecture from 10 in 1997 (Carpenter, 1997) to over 60 in 2012 (Abdullah, 2014). Nearly a century after the "persistent gap" emerged, the wave of success of design-build in education is making a serious attempt to build on the work of the 1960s radicals. The concurrent defining and development of "live projects", defined as "a type of design project that is distinct from a typical studio project in its engagement of real clients or users in real time settings..." (Sara, 2006), has added another layer to the educational debate. Some assert that "live projects" accomplish many of the same learning outcomes of "design build" projects, which differentiate by focusing on "the opportunity to gain hands-on experience of basic construction methods and the change to see real-world consequences of [...] design decisions" (Ockman, 2012, p. 286), without the drawbacks, most notably the inherent risk of construction projects (Salama, 2016, p. 245). This risk-averse approach mirrors that of the professional split of architecture and construction (Gluck+, 2013). The most successful "design build" courses are rooted in a deeper social activist movement that emerged in the counterculture movements of the post-war era. Often sited as the most established programs in the United States, the Yale Project, the Rural Studio in Alabama, and the Neighbourhood Design Studio/Jersey Devil Group in Washington, continue to embed the social activism of the 1960s progressive thinking (Brown, 2012; Carpenter, 1997; Ockman, 2012). Several other design-build actions have emerged in schools of architecture across the globe. Of particular interest is the development of design build approaches on ideological substrates that have very little to do with 1960s radicals, and look to re-engage with earlier models of Gropius and the Bauhaus, who considered the experience of making a means to test the theoretical learning of a student (Carpenter, 1997, p. 17): Studio 804 in Kansas and the AA design-make program based at Hooke Park in Dorset, employ this approach.

\subsection{Christopher Alexander: a coherent ground for a sustainable future.}

No one today like Christopher Alexander both incarnates the stream of radical alternative to conventional architecture described above, and transcends it by shifting the focus to the nature of the act of building and its value for the human being.

We now understand that efficient complex systems are those where parts are independent from each other and yet generate coherence in the whole. The one ahead is a different, living, interconnected world, whose challenges require by their same nature a holistic understanding and pathway to knowledge (Morin, 2002). Thinking of education for the next generations of architects and builders, we need to shape supremely gifted individuals capable to feel, understand and inspire the coherence of the whole, in order to be 
responsible to the people and the land. The reality of such complexity and interconnectedness requires a higher understanding of what sustainability means, in ways that go far beyond the mechanistic accumulation of "smart" technologies and "energy efficient" solutions.

More than 10 years ago, lecturing an audience of sustainability specialists, Christopher Alexander proposed a leap into a more profound notion of sustainability. He was in a good position to do that, since at that point he had already generated an extraordinary intellectual production coupled with and supported by the evidence of a rather conspicuous practice of direct construction, entirely dedicated to understanding the act of building as a phenomenon of life in its broadest and most meaningful sense. In that lecture, Alexander started off proposing a different meaning for the notion of sustainability, one that "refers to the wholeness of the land, the extent to which we see our land (rural, urban, or wilderness) as sacred, and the extent to which we treat our interaction with the land as a sacrament. The extent to which we recognize the beauty of what we make in the land is of paramount importance. It is not just an add-on or a luxury. Rather, it goes to the core of what sustainability really is." (Alexander, 2004c). From the very beginning, Alexander re-defined sustainability into a more profound and comprehensive notion: beauty.

It is along this line, and at this level only, that we can find the ground for a fresh exploration, effectively a new agenda in the architectural profession, education and research for the $21^{\text {st }}$ century. The program in Naples emerges from the urgency of this challenge. We want to open up a space for the free exploration of an authentically alternative, deeply human pathway to building our place on Earth in the age of urbanization, one that makes us once again capable of providing "healing of the whole: the land, the people, the existing structure of the city" (Alexander, 2002b).

\section{Re-thinking the building process: Christopher Alexander and the timeless pathway to generating beauty.}

\subsection{Radicalism and continuity in Christopher Alexander.}

Christopher Alexander's writings and built works are characterized by a unique blend of radicalism and continuity. If radical is his departure from the mainstream of conventional modern architecture, equally strong is his attempt to re-knit the broken thread with premodern or traditional building processes. In Alexander, however, everything comes as a consequence of an investigation of the "timeless" forms of the act of making, which is seen as the foundational expression of the relationship between human beings and the land. It is this character that distinguishes him from other more formalist radicalisms such as Paolo Soleri's in Arizona; equally large is the distance that separates him from the many neotraditionalisms that characterized the "post-modern" period of western architecture in the 1980 s and 1990s. As much as he is interested in the authentic expressions of the past, his focus is predominantly on the process that generated such beauty, its "unfolding" nature: "In the mechanistic view of architecture we think mainly of design as the desired end-state of a building, and far too little of the way or process of making a building as something inherently beautiful in itself. But, most important of all, the background underpinning this goal-oriented view - a static world almost without process - just is not a truthful picture. [...]. For in fact, 
everything is constantly changing, growing, evolving. [...]. In our profession of architecture there is no conception, yet, of process itself as a budding, as a flowering, as an unpredictable, unquenchable unfolding through which the future grows from the present in a way that is dominated by the goodness of the moment" (Alexander, 2003, p. 12). Such antiformalist character opens the way for time and change as key-dimensions of the act of building, and with it to complexity, uncertainty, evolution and resilience. This character, together with its both holistic and evidence-based nature, makes Alexander's work uniquely suited to lay the ground for a profound shift in both architecture and architecture education, one capable of tackling the challenges of the $21^{\text {st }}$ century.

\subsection{Christopher Alexander: stepping-stones of a way forward.}

Christopher Alexander's production so far constitutes a remarkable written and built work that spans from the early 1960 s to our days, culminating in the 2000 s with a monumental fourvolumes magnus opus entitled "The Nature of Order" (Alexander, 2002a, 2003, 2004b, 2005) and the latest book: "The Battle for the Life and Beauty of the Earth" (Alexander, Neis, \& Moore-Alexander, 2012). Even a superficial description of such work would go far beyond the scope of this paper. Fortunately, Alexander himself embarked many times in making an operational synthesis of his own findings in terms of guiding principles; in particular, we make reference to: a) A rebuttal to William Saunder's review of the first volume of "The Nature of Order" (Alexander, 2002b); b) an unpublished transcription of his lecture at Harvard in 1982, a few days before the notorious debate with Peter Eisenman (Alexander, 1982); c) his interview after the publication of the fourth volume of "The Nature of Order" (Alexander, 2004a); d) his lecture on sustainability and morphogenesis delivered in Bristol in 2004, UK (Alexander, 2004d); e) a summary of findings from "The Nature of Order" (Alexander, 2007); f) his latest writing published, addressing the relationship between beauty on the Earth and "the force of what was once called God" (Alexander, 2016).

We present here an open list of Alexander's principles, rephrased in a language that, we hope, is suitable to ground a new education program such as that now shaping up Naples.

\section{PART A}

What is beauty?

- PRINCIPLE N.1: The class of phenomena that are beautiful.

There exists in the natural, cultural and physical world, a class of phenomena that are beautiful, the beauty of which has essentially to do with our everyday material and spiritual life. All those who make things work in that domain of our physical world. We want to understand what characterizes such phenomena, how they occur and change, and how, as makers, we can help in the process.

\section{- PRINCIPLE N.2: A new cosmology.}

"Cosmology" is a conception of the physical universe, essentially a science of what it is made of and how it works, which allows us to approach a problem in it. The present cosmology, based on Cartesian mechanistic science, offers little help in approaching that class of phenomena, those that can have beauty. A different cosmology, based on complexity, uncertainty and change, is now emerging in various areas of science. That calls makers as well to start afresh. We explore a non-conventional agenda in education and research for making, which poses beauty and its generative process centre stage.

- PRINCIPLE N.3: Day-to-day, minute functionalism.

We are primarily interested in the minutiae of the acts of making and inhabiting the physical world. We acknowledge that life takes place by continuously adapting the surrounding environment in an uninterrupted everyday process of adapting by making. We intend making as an adaptive process of change that predominantly occurs in the dimension of the ordinary. 
- PRINCIPLE N.4: Objective nature of quality.

Ordinary spaces have a quality whose value, once explored at the appropriate level, belongs to all human beings. As a consequence, spaces that embed such quality are objectively good for everyone. It is because that quality exists that makers can at each step in the process of change add to and expand-rather than detract from and reduce-the original quality. We aim at defining and measuring the objective quality of space that emerges at the level where human beings share a common canon of values.

- PRINCIPLE N.5: Holistic nature of space.

The quality of space is holistic in nature. It is essentially grounded on our individual and collective self, where functionality, ornament and beauty are just different names for the same thing. Developing an appropriate awareness of our individual and collective self is essential to understanding the quality of space. We explore our individual and collective self in space as a fundamental way to understanding how to make things.

- PRINCIPLE N.6: The quality of space comes prior to function.

That quality which we call "beauty" emerges, in the physical world, as an inner order that is spatial. Such order is recognizable in the recurrent manifestation of certain geometrical configurations and patterns of use and shape. Good functionality, sense of belonging and wellness are by-products of that: that is why the order of space comes prior to function and is the foundation of all. We focus on the order of space that recurs in phenomena of beauty: what it is made of, and how can we help it to emerge and expand over time.

- PRINCIPLE N.7: Testing the quality.

The way the quality of space appears to us is by generating - and being generated by - authentic feelings that connect us to the place and the others in a profound way. Such feelings are the emotional construct that constitutes our sense of belonging and, at the same time, our identity: rather than being idiosyncratic, they regard us all. We pursue the ability to recognize, trust and develop our own feelings as a reliable ground for testing the quality of space.

\section{PART B:}

How does beauty occur and how can we help in that?

- PRINCIPLE N.8: Careful choice.

The quality of spaces does not come by design: it can only emerge during the process of making. Such process occurs at the moment of building something in the first place, as much as in the many moments when we adapt it to the changing circumstances of life. We experience beauty in space when we see that everything around has arisen by careful choice and restless consideration of both the place and our own self. We are interested in the process of fine-tuning that creates a place: in a short-term "project" scenario, we look at how to design and deliver such process; in the longer-term, and truly "evolutionary", we explore the conditions that allow such process to occur in a predominantly self-organized way.

- PRINCIPLE N.9: The "unfolding" nature of beauty generation.

The generative process of phenomena of beauty is characterized by "unfolding" in time. It is, essentially, a process of adaptive transformation. That happens in steps, whereby each step expands the pre-existent beauty and, in itself, is complete and makes full sense. As a consequence, at any step beauty is built on the ground of the previous, and errors, feedbacks and uncertainty are constituent parts of the process. We test and explore the unfolding nature of beauty generation both in the process of making and in that of teaching how to make.

- PRINCIPLE N.10: The healing nature of making.

Generating beauty essentially means "healing" both the space and the community of makers and users. "Healing", in turn, essentially means "reunifying what was previously separated". A beauty generative process is one where conventional separations (for example between builders and designers, designers and users, professionals in different disciplines, places and times of decision/authorization/implementation) are overcome and reunified at each step in a fully integrated whole. We explore how to reunify design and construction at each step of the process of making.

- PRINCIPLE N.11: The reality of the land and that of what we want to make.

Primarily, healing in making has to do with understanding the order of the space (existent in the land) as well as that of what we want to make (existent in ourselves), and then with reunifying the two in a coherent whole. For that reason, we investigate all means to make such two orders explicit, and then reinforcing each other.

- PRINCIPLE N.12: Mocking up.

In a conventional building process, the means of most separations is the drawing. People make decisions in different places, at different times, from different points of view, always by looking at drawings. In a beauty 
generative process, drawings must be used as an integral part of making, which essentially is a physical, on-site, trial-and-error process based on the use of full-scale physical mock-ups. We practice the on-site, trial-and-error, full-scale mocking-up as the core system of decision making in the building process.

- PRINCIPLE N.13: Construction at the core.

For all that is mentioned above, we propose direct hands-on construction as the core of the act of making. That is where and when everything happens; the building yard and the actual act of building are the place and moment where the healing reunification occurs. By placing construction at the core of our educational program we produce a revolutionary act, which subverts most of conventional architectural education, and we look into a truly human, sustainable $21^{\text {st }}$ century future. We practice direct construction as the all-encompassing environment of making.

\section{The new Master in Building Beauty at UniSOB in Naples.}

\subsection{Background.}

The program proposed is a "University $1^{\text {st }}$ Level Master" in the Italian nomenclature. Sitting in the second cycle of the Bologna framework, the $1^{\text {st }}$ Level Master can only be delivered by Institutions holding University status over a minimum period of one year, offering 60 ECTS credits to students holding a "Laurea" (Bachelor) or equivalent qualification. In the Englishspeaking world, it is equivalent to a post-graduate specialist program.

The idea underpinning it is of a different, both holistic and scientific approach to architectural education, one that poses the ordinary environment at centre stage and focuses on the adaptive process of building and change, and the role of design in it, one where life is respected and enhanced in all its forms and "beauty" becomes a tangible objective of social and ecologic pursuit as well as a matter of serious scientific investigation. This idea has been with the authors for long time. The opportunity to develop it matured in spring 2015, in collaboration with UniSOB, through the realization of a program, the main principles of which seemed fitting well the local values and resources and were enthusiastically embraced. Since then the program has been progressed considerably: it is now expected to be launched in January 2017 to start in Naples in October 2017.

\subsection{Structure.}

The proposal is for a one-year, intensive, residential program, taught in English and specifically designed to appeal to international students. It will be delivered within the UniSOB University's historical home, a magnificent XVIt ${ }^{\text {th }}$ century monastery sitting on a hill in the heart of Naples's "Spanish quarter" and overlooking the Gulf and the Vesuvio volcano (fig. 1). 


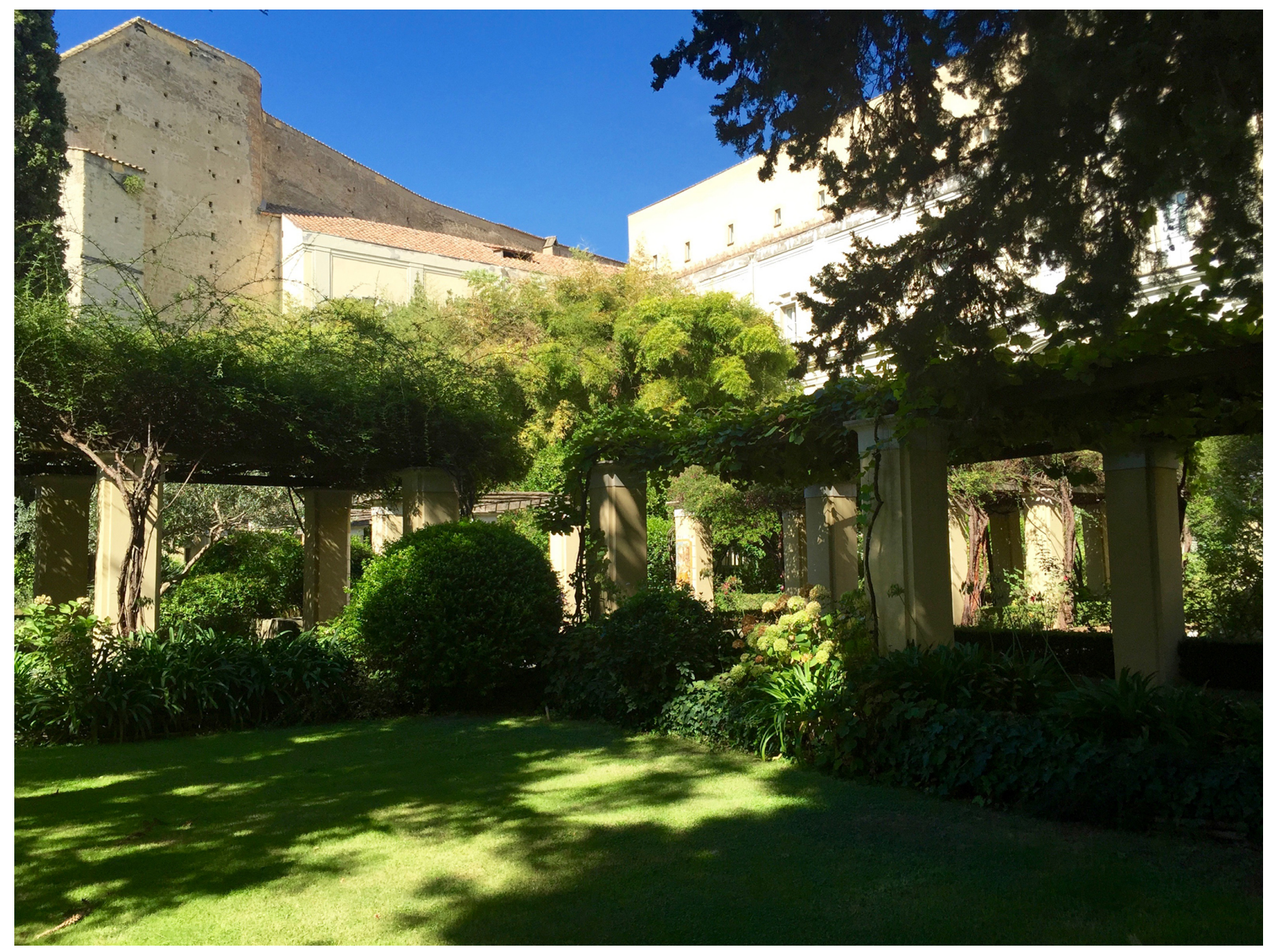

Figure 1: View of the Suor Orsola Benincasa monastery: main court and garden.

This setting makes possible a disarming and robust continuing investigation into Alexander's ideas and how they should be taught, and supports a promising research agenda for architecture and urbanism. The program's structure (fig. 2) can be described in terms of time and type of activities: firstly, in the first semester students will take advantage of the exceptional location and learn from the monastery's beauty, while in the second they will try to expand such beauty by building in it; secondly, the student's experience will be in three main areas: construction, seminars and self \& space.

Students will engage in direct construction from the first to the last day of the program. Here, ornament is considered an integral part of the construction, reuniting what was dogmatically separated at the dawn of the modern design age. In the first semester students will study and map the monastery from the point of view of its historical building techniques and materials, to then engage in a full-scale replication of some elements of it, i.e. their identical full-scale in-lab reconstruction. In the second semester, students will work in the courtyard, an open space located right in the core of the monastery, which will be the program's "home"; here they will work on the design and actual construction of ameliorations to the courtyard and the adjacent service buildings. The identification of the theme for the second semester construction project is part of the work that students will do in the first semester, involving various stake-holders from within and outwit UniSOB itself. Finally, as part of their construction experience, students will cultivate land in the historical "Cook's Garden" of the monastery, adjacent to the courtyard: here they will grow food that then will be cooked and consumed collectively, in collaboration with UniSOB's established research laboratories on 
Mediterranean diet and botanics; students will learn by hand-practice the intricate webs that make the land a living structure, a whole to be understood and enhanced.

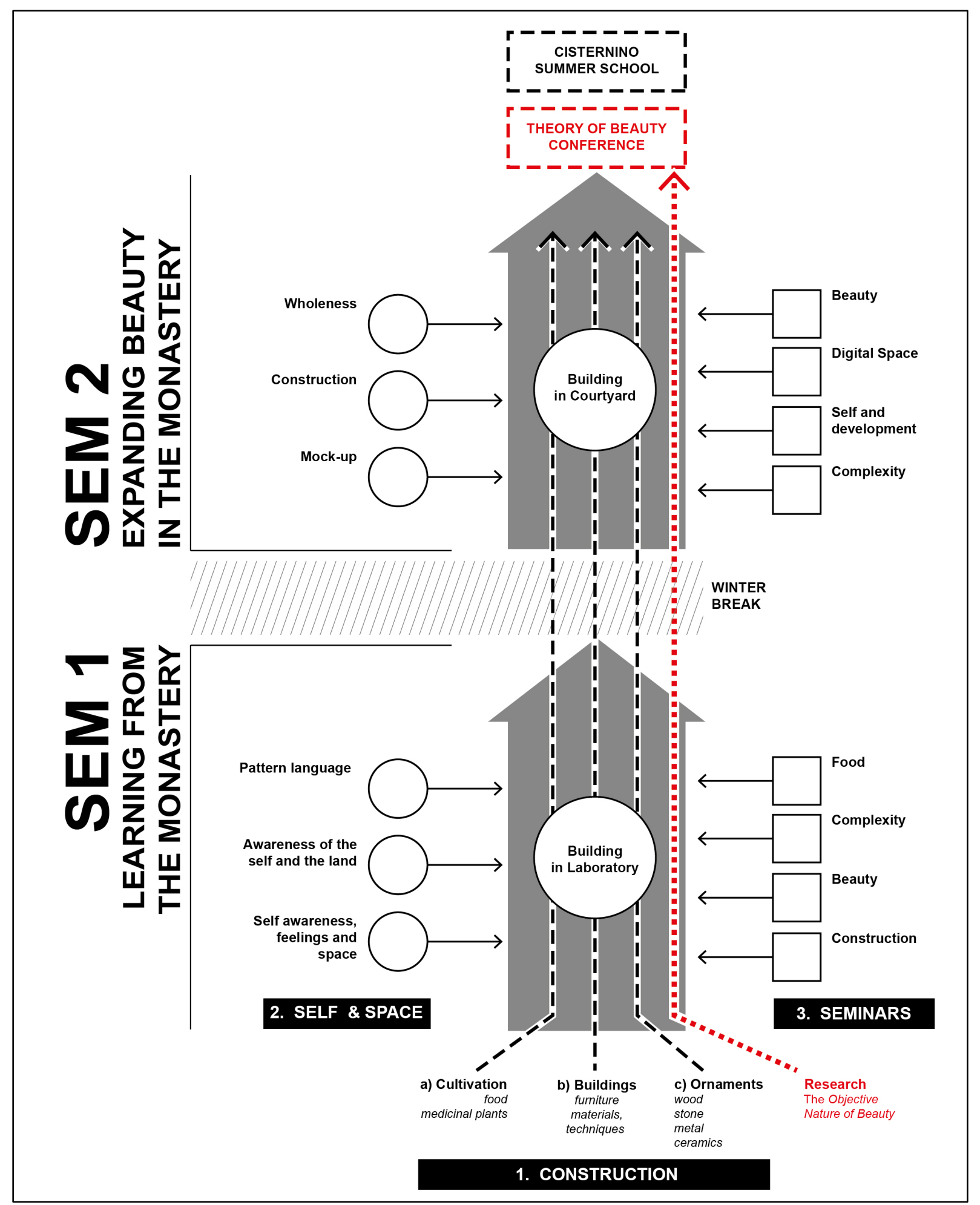

Figure 2: Building Beauty: the structure 
On top of direct construction, students will be engaged in two other lines of learning experience: a) Seminars: a series of interactive sessions targeting both core-concepts of Christopher Alexander's theory, delivered directly by CES colleagues, and other subjects including: global and Mediterranean food system and cultivation; physics of complexity; evolutionary biology; international cooperation, humanitarianism and development; web design, digital and physical space; traditional Mediterranean urban morphology and vernacular architecture; philosophical counseling and oriental philosophy; b) Self and Space: a series of practical workshops aimed at raising the awareness of our individual and collective feelings. Feelings will be explored in relation to space, the body-mind, and the way they interact in the hands-on physical work of making artefacts. Such two lines of activities are meant to provide the knowledge required to observe, understand and act within a complex system where elements have individual and interrelated value, and where observation, understanding and action are related to our experience of such elements and their interrelation.

Finally, two major events will conclude the program: a) in the "Theory of Beauty Conference" students will contribute and discuss their experience in a large international and interdisciplinary conference with world leaders from academia as well as the profession; $b$ ) In the "Cisternino Summer School", a two-weeks residential stage in an old "masseria" (country house) close to the village of Cisternino in Puglia, students will learn from a local masterbuilder the construction technique of the traditional "trulli" houses.

\subsection{Syllabus.}

The syllabus (fig. 3) spans over two semesters of twelve weeks each, starting in late September 2017. Activities in the three streams of construction (yellow), seminars (purple) and self \& space (blue) run in parallel over both semesters, and are concluded by the Theory of Beauty Conference and the Cisternino Winter School.

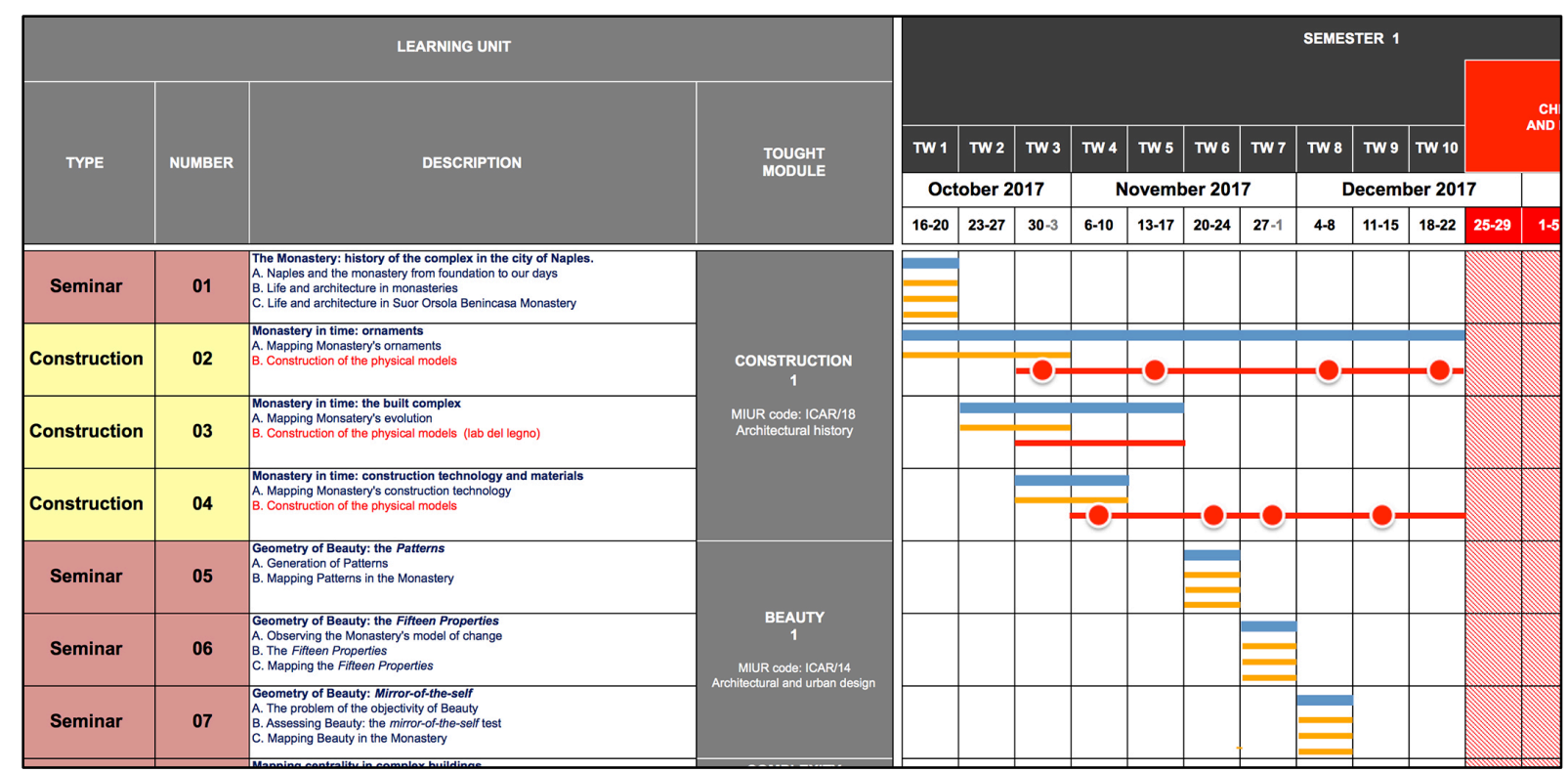

Figure 3: Building Beauty: extract of the Syllabus in the first semester. 
The first semester is about learning from the monastery. Students begin with a seminar on the monastery's history, life and architecture in Europe and Italy, with a focus on the Benincasa complex in Naples. Construction starts immediately the week after and lasts for the rest of the semester: here students are driven to map the monastery's ornaments and components (walls, vaults, flooring, windows, stairs...), to then replicate some of them fullscale in the construction lab; in so doing, students will learn to build according to traditional construction techniques, experiencing the whole process of sourcing, treatment and deployment of all materials involved, "from the cave" to the finished artefact. This is offered in close collaboration with UniSOB's world leading School of Conservation and Restoration of Cultural Heritage, with immersive sessions run in their unique laboratories of metal, stone and woodworks. In parallel, as an integral part of the construction stream of activities, students: a) build a physical model of the monastery's evolution in time; and b) start their cultivation experience. This latter activity is a full project of food and plants production directed by UniSOB's research laboratories of Botanics, Mediterranean Diet and Food: here students shape their own project in a fully tutored environment, and directly produce food/medical essences in the terraced University gardens overlooking the gulf of Naples. Construction and cultivation occupy the prevailing part of the standard week of studies, leaving the rest for seminars and self \& space activities (fig. 4).

\begin{tabular}{|c|c|c|c|c|c|c|c|c|c|c|}
\hline & \multicolumn{2}{|c|}{ MONDAY } & \multicolumn{2}{|c|}{ TUESDAY } & \multicolumn{2}{|c|}{ WEDNESDAY } & \multicolumn{2}{|c|}{ THURSDAY } & \multicolumn{2}{|c|}{ FRIDAY } \\
\hline & AM & PM & AM & PM & AM & PM & AM & PM & AM & PM \\
\hline CONSTRUCT & & & & & & & & & & \\
\hline CULTIVATION & $: 9$ & & & & & & & & & \\
\hline SEMINARS & & & & & & & & & & \\
\hline SELF\&SPACE & & & & & & & & & & \\
\hline RESEARCH & & & & & & & & & & \\
\hline
\end{tabular}

Figure 4: Plan of activities for the standard week of studies.

In parallel to the hands-on work in the construction lab, in the first semester students are exposed to a series of seminars the aim of which is to gradually introduce them to the practice of Christopher Alexander principles (Alexander, 2002a, 2003, 2004b, 2005). Such core-syllabus is delivered in weeks $4-9$ by some of Alexander's life-long collaborators: rather than theoretical talks, these seminars are practical investigations through which students will learn how to "see", feel and map the living structure of beauty as appearing in the monastery, where it is actually present to a uniquely high degree.

The practice of feeling beauty requires skills of body/mind awareness that, largely present in childhood, are nevertheless mostly lost as we grow and definitely excluded in conventional architectural education. Students go through a process of recovery of such skills in a series of self \& space workshops that run in weeks 2-9, including dance/drama/art therapy sessions, as well as an introduction to feeling maps, philosophical counselling and the philosophy of imagination. 
The second semester is a fully integrated experience aimed at the realization of interventions in one of the monastery's courtyards which is assigned to our students as their home environment and "building yard" (Alexander, Davis, Martinez, \& Corner, 1985). Contrary to the first semester, when construction is about the replication of building components found in the monastery through the work of pairs of small groups in the construction lab, in the second semester students collectively approach the realization of an actual intervention in the courtyard, the nature of which is explored in the first semester. Here self \& space and construction are integrated in the single flow of making, while seminars, covering a wide range of subjects, are timely provided to respond to students' emerging needs. Leading international scholars from different backgrounds will offer the students the opportunity to explore the potential of a truly holistic approach to design and construction to tackle important challenges in the current international agenda of sustainable architecture and resilient communities. Seminars' invited scholars do not just come, talk and go; they are instructed not to prepare presentations upfront, but rather spend one full morning engaging with students in the building site, reflect in the afternoon and then manage, over a prolonged dinner, a talk-discuss-engage session with students and the external public. This last stage of the visit, which recalls a "cenacolo" format ${ }^{1}$, can be supported by audio-visuals if necessary, but is meant to maintain an informal and pleasant character taking advantage of the magnificent scenario of the monastery's terraces and breathtaking historical setting.

The program culminates in the "Theory of Beauty" conference. The exploration of beauty is not only practiced as an essential part of the construction experience, but also as an actual avenue of scientific research entitled "The Objective Nature of Beauty": here, state-of-the-art technology will be deployed to investigate beauty in the cognitive process associated with the human-environment interface, in collaboration with SOB's research hub "Scienza Nuova". Students are integrated in such stream of professional research activities aimed at peerreviewed publications, and have a unique opportunity to understand, by first hand practice, what professional research means. Students at the conference have a chance of presenting the outcomes of this research, as well as comparing and discussing their work with worldclass international scholars in the field.

Finally, the Summer School runs in weeks 11 and 12: students move to Cisternino, Puglia, one of the most beautiful towns of southern Italy, for a one-week intensive building experience. They reside in an ancient "masseria" (farm house) and learn from an old masterbuilder the art of building "trulli", the traditional round houses typical of the place (fig 5): this full-immersive experience of direct construction, communal life and celebration concludes a very intensive year of course.

\footnotetext{
${ }^{1}$ The Italian word "cenacolo" (cenacle) indicates a circle or group of people sharing an intensive discussion on topics of common interest, in an informal setting. The modern meaning of the word is a translation of the original referred to the "cena" (dinner) or, indeed, the dining room itself.
} 


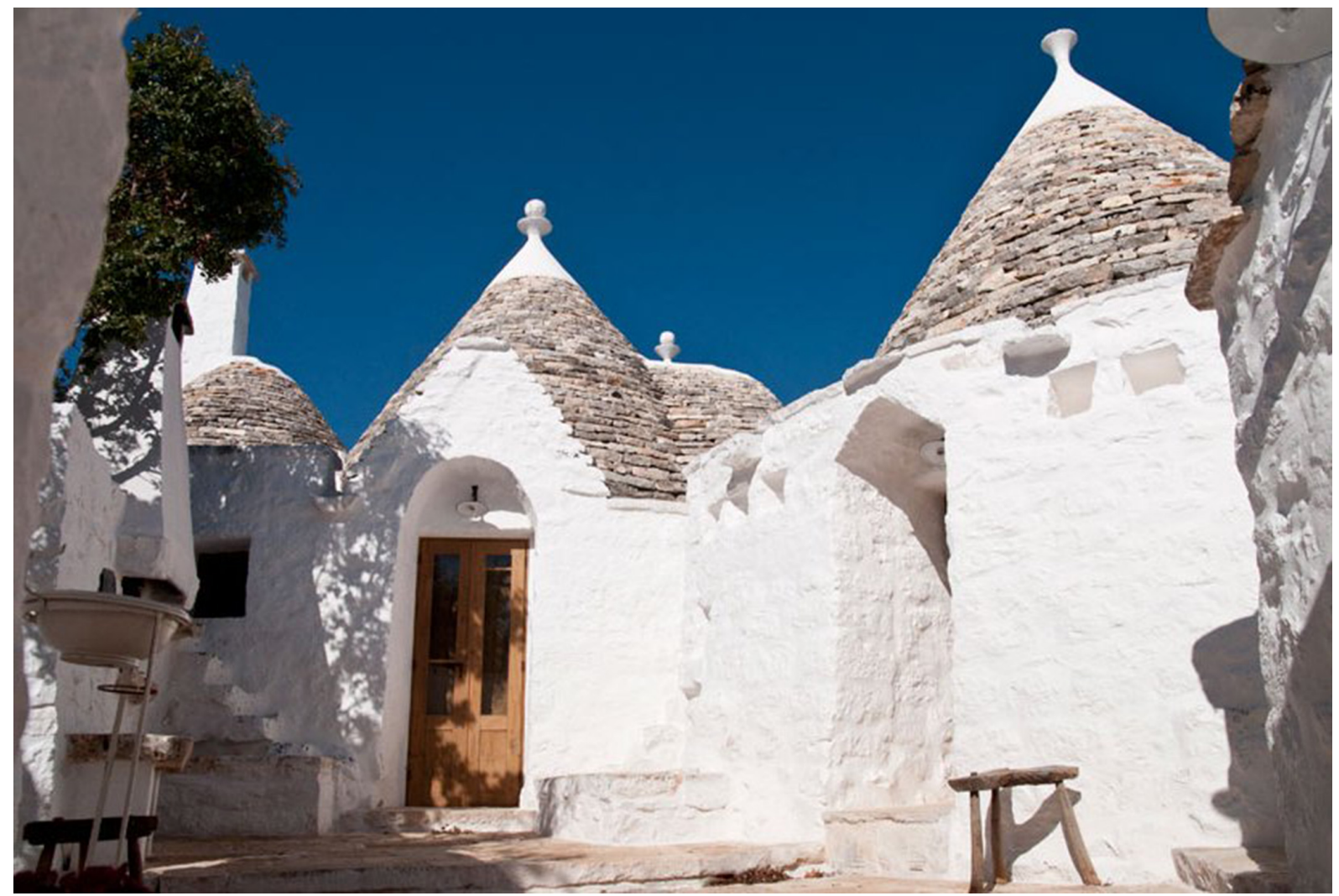

Figure 5: Traditional "trulli" in Cisternino: the Summer School construction theme.

\section{Foundations of the pedagogical model.}

Christopher Alexander is a precursor at many levels. Firstly educated in chemistry, mathematics and physics, he understood with Quantum Physics the central role of uncertainty in matter transformation. As an architect, passing from the micro to the human scale where the physical dimension of the outer world intermingles with the inner emotional and cognitive dimensions of human life, he naturally could not switch back from a probabilistic to a deterministic vision of reality. Quite on the opposite, a fundamental reflection on the living experience at macro level helped him to see the profound unity of the world across scales. That is where his contribution to software design and design in general comes from: not structures conceived in a deterministic way and handed on to engineers for mere implementation, but the profound awareness that complexity and uncertainty can only be tackled getting closer to the objective step by step, by successive approximations, through a fundamental principle of iteration (or, in his own words, of "unfolding"). He interprets the process of making as a spiral that converges in cycles towards a solution, where each cycle must have full meaning for those involved and generate in them a sense of accomplishment.

Our teaching approach starts from there. We draw from Project-Based Learning approaches and propose an update with the principles of Agile Design, always keeping in mind that we work in an educational framework, not commercial or professional only. 


\subsection{Project-Based Learning and architectural education.}

Within the area of educational sciences in the past few years, a large debate emerged on the need for a swift paradigm shift, from a cognitivist/transmissive pedagogy, which generates an inert kind of knowledge, to a constructivist one: here learning does not occur by reception; instead, it is constructed by the learner through a practical process of discovery, which generates a meaningful type of knowledge (Bruner, 1961, 2009; Reeves \& Hedberg, 2003).

Architecture students in particular, because of their inherent proximity to the act of making, could benefit from a paradigm shift towards such experiential learning approach, one characterized by a strong emphasis on the actual practice of building. To successfully achieve this goal, we propose a Project-Based Learning pedagogy (PBL). PBL fosters learning, both in terms of contents as well as skills, engaging students in the development of projects and the resolution of the many authentic problems attached to them which, in turn, are a strong stimulus for learning (Blumenfeld et al., 1991). In this sense, a PBL strategy engages students in problem-based learning too, a pedagogical innovation firstly developed, significantly, in the medical field (Barrows \& Tamblyn, 1980). The need to solve problems triggers in students deep involvement and stimulates them to learn the contents that are functional to solve the new problems: this is the core of Problem-Based Learning. Students learn the contents not in order to repeat them to an examiner, and especially they don't resolve problems in order to check if they had learnt the contents; rather, the process is turned upside down: first the problems, which generate a need for learning, then the contents: by that, learning becomes meaningful.

PBL is very effective in supporting a long needed shift towards a learner-centred approach aimed at developing her/his specific talents: students developing a project find their space and rhythm according to their own type of intelligence (Gardner, 1984).

The continued attendance of a complex arena dominated by uncertainty, and the adoption of effective strategies to reach a solution in an interactive and incremental way, contributes to equip the student immersed in a PBL experience with " $21^{\text {st }}$ century skills" (Bellanca, 2011). That, in turn, helps her/him to navigate an entirely new system of knowledge, where access to knowledge regularly occurs from many different directions and levels at the same time. Living with uncertainty and complexity implies tackling problems: that is the spring to search for the information and tools that are needed, which in turn triggers learning by discovery. In the Internet age, the challenge becomes interesting. To reach quickly and timely the right information may, at first, appear confusing: you get closer to the solution, but the knowledge that is built appears fragmented, not organically shaped. Only small bits of information become visible, which may be useful to solve a particular step in the process, but still seem not comparable to the organic knowledge achievable by orderly reading a book chapter. And yet, behind such discomfort we can see the formation of a deep understanding: not the know-about, but rather the know-how. Many specific learnings fit to solve similar problems create a network of knowledge that is essential for the resolution of a class of problems: we witness the emerging of a network of expert knowledge, skills and know-how. Not only that. Repeated investigations, even regarding the same information, hardly produce the same range of answers: on one side the disorientation, on the other the wealth of perspectives and points of view. Wittgenstein's metaphor of the criss-crossed landscape fits perfectly the case (Wittgenstein, 1953). Ultimately, "by criss-crossing a conceptual landscape in many 
directions, knowledge that will have to be used in many ways is taught in many ways" (Spiro \& Jehng, 1990, p. 171).

Among all kinds of projects, those aimed at making are the most valuable in an educational environment. A process of real construction is authentic, and authentic are the problems that makers face in making: such problems are typically "wicked", meaning for example that they do not have one true-false solution, nor even a clear and univocal formulation (Rittel \& Webber, 1973). As a result, makers learn not to seek the final perfect resolution, but instead the best possible in the given situation. Far from the determinism typical of mathematical problems, the solution of which requires a precise algorithm, wicked problem`s are complex and uncertain in nature and may call for a heuristic approach. The continuous appearance of the uncertain and the undetermined, which may in the first place look pathological, is in fact physiological and typical of the real work of all practitioners, architects in particular. In order to navigate this kind of problematic arenas, we need skills that, mostly ignored by conventional teaching, become central in a construction-oriented approach. It is only by educating them to engage in the whole cycle of production, with its typical adjustments along the way, and progressive convergence towards the needs and visions of the users, that architects can get closer to a true creativity, meaning one that does not elude but rather takes advantage of uncertainty. It is this way to learning, through which students build their knowledge by means of the construction of an artefact, that essentially incarnates what Seymour Papert defines "Constructionism": "Learning is most effective when part of an activity the learner experiences is constructing a meaningful product" (Papert, 1987).

In sum, the PBL approach is fit to deliver a constructivist/constructionist approach in any teaching context, and particularly so in that of architecture education where the construction of a meaningful product is intended to be the ultimate overarching objective of the work.

\subsection{Project Management is not Project-Based Learning.}

PBL and Project Management (PM) should not be confused. In all evidence, failing in this distinction has often caused severe problems to PBL in practice. In short, PM is aimed at the production of products or services, while PBL of learning outcomes: the former applies to industrial/professional environments, the latter to educational. The mere generation of a project, however successful, does not necessarily signal a successful educational experience, which can only be measured in terms of personal growth throughout the learning process. A group of learners that ultimately manage to get a project done may be quite different from one whose learning experience is truly based on developing a project; of such difference we need to be aware when designing any PBL experience, and even more so one in architecture, such as "Building Beauty".

\subsection{Authentic assessment: rubrics and self-making in PBL.}

Assessment techniques that are effective in cognitivist/transmissive approaches do not necessarily work well in constructivist environments. Tools such as the check-list, performance list and especially the rubric, make it possible to assess a student engaged in authentic tasks (Arter \& McTighe, 2001; Popham, 1997). Through procedure of authentic assessment, students producing a performance receive a feedback that allows her/him to monitor what $\mathrm{s} / \mathrm{he}$ is doing and get better at it. This is the key point in a student-centred 
approach, as opposed to program-centred: the student is given a tool for self-assessment that makes her/him independent and responsible while, at the same time, the teacher is provided data to keep control over the actual learning process and intervene on it, if necessary.

Here, transparency is pivotal. Assessment tools like rubrics must be shared and discussed with students at the beginning of their performance, or better built with them. The rubric in particular is a tool whereby criteria of assessment are developed in agreement between students and teacher, and used to chart both progress and output against variations in the students performance of the criteria on which s/he now has ownership: the student understands them and importantly believes they are worthy and meaningful evidence of learning. In architectural education in particular, where what constitutes a positive or a negative is very rarely argument of discussion and values are surreptitiously passed on from "master" to "apprentices" by sheer imitation, the act of involving students in a detailed process of definition with regards to what is relevant and what isn't in what they do, and to what degree, and how both can be objectively described, has a profound educational meaning and a revolutionary impact on conventional practices. The rubric has to be intended as a contract between teacher and student that, once agreed, can only be amended after a further agreement. Constant self-monitoring and good rubric design (for example linking the "important elements" that characterize the quality of the performance to key-learning objectives) turns rubrics in an effective tool for both developing and assessing students' abilities.

\subsection{Project-Based Learning in practice.}

Transferring structures that are fit to produce projects, i.e. Project Management (PM) structures, into an educational framework is crucially important in order to give teachers a solid ground for action. That implies the consideration that a project is not realized in one go, but rather is a process with its own phases and a life-cycle. A reference in that, widely adopted in Italian public secondary schools, is offered by the "Lepida Scuola" model (E Zecchi, 2007; Enzo Zecchi, 2012): drawing from the phasing proposed by the Project Management Institute (PMBoK, 2000), the Lepida Scuola model identifies four steps:

1) Ideation: definition of the project vision. The risk in this phase is that in absence of a clear framework for action students can easily feel disoriented and get lost. In the Lepida Scuola model such framework is offered in the form of a user-oriented analysis called "Split Tree", where user's needs are identified and then associated with required project's design requirements.

2) Planning: definition of all the resources, human and material, for the execution. It is important that the students are aware that any plan is there to be changed, if necessary, and that change is a constituent and creative part of the process, rather than a fault. In conventional design, this is when the architect designs the building, the drawing time. In Alexander, this is when the architect designs the process.

3) Execution: realization of the project. In Alexander, this phase expands to cover in one single stream of trial and error both the conception and the actual construction of the building. In many cases, decisions are taken while constructing a full-scale mockup of the building, instead of the real one, in order to allow maximum flexibility in the 
trial and error process. Side-by-side with the built products, in Lepida Scuola the student has to also produce a Narrative (for example in form of diary), which is where the reflection in the next phase finds a reference ground.

4) Closure: at the end of the cycle the student is tasked with reflection and communication: the retrospective component of this phase is of great educational value and must be structured conveniently. Experience tells us that the main problem in passing from a commercial/professional to an educational setting is not as much that of teaching students to make things, which they are normally very keen and good at, as that of bringing them to reflect during action. Reflection is therefore a specific component of the educational process; reflection may greatly benefit, in this phase, from association with tools of authentic assessment such as rubric.

One problem that has recursively emerged in practicing the model is that Ideation and Planning are very sophisticated pieces of work that often students struggle to accomplish in the first place. Though at higher education level the issue is less relevant, it is worth noting again that Alexander's approach goes much more quickly into the execution phase and that this phase is much richer and larger than a mere implementation of decisions taken already at the planning phase. By effectively moving the creation of the product into the execution phase, Lepida Scuola's model gets very close to Alexander's, and both in fact move towards the Agile Project Management attitude to resolve problems by recursively addressing them in an empirical environment.

\subsection{Towards a synthesis: principles of an Agile approach.}

The term "agile", as referred to Project Planning, appears in the late 1990s-early 2000s primarily as referred to software development projects, but the type of problems they tackle are common to a variety of different areas. The "Agile movement" stemmed from an effort to find a common ground among various approaches to software development, which culminated in 2001 in a Manifesto (Beedle et al., 2001). The main point of the approach is to acknowledge the essentially unpredictable nature of a project and manage it without following a strict schedule but keeping a responsive attitude to changes (Highsmith, 2009). The effort was made relevant by the recursive failure of projects, especially large projects, that were undertaken according to conventional PM approaches, called "waterfall" (Sutherland, 2014). In a waterfall approach, as we have seen above, the development of the project is expected to follow a rigid sequence of phases: starting, planning, executing and closing. In a real project, however, a first mistake is the assumption that characteristics and requisites of the final product are known at the outset: in practice, in fact, the product takes shape and gets defined along the way, in time: its characteristics change continuously in the process, and that is norm, not exception. A second recurrent mistake is to invest an overwhelming amount of resources in the planning phase: considerable sums of money, high level specialisms, long periods of time, are spent to achieve plans which define every detail as a way to get total control on the process. Hundreds of pages project plans. It turns out that the perfect project plan, like the perfect building plan, does not exist.

It is not about ideation or planning mistakes: it just the way the products takes shape. At the beginning of the project the product's features and functionalities are rarely defined, the client himself does not know exactly what he needs. The project must be laid out so that such characteristics of the product arise step by step in the process: it is a discovery and fine- 
tuning process that needs to be treasured and structured, rather than opposed. That is a radical departure from conventional PM: not a process of definition and painful correction, but instead a continuous definition and construction while making, integrated in execution. This shift crucially implies the capacity to assess critically what we are doing, spot the opportunities to do it better, immediately identify and prioritize that $20 \%$ of product's features that hold the $80 \%$ of its value. An invaluable exercise for critical thinking!

Unforeseeable variables emerging along the way may also include: technologies, which may be discovered or may change; team members, who may know and coordinate differently with their inevitable conflicts and unexpected synergies; new ideas, which arise during the development of the product; difficulties or constraints emerging in the surrounding decisional environment: all that contributes in determining a general climate of indetermination and uncertainty around the development of the product. It is the complexity of the real world, of daily life, where problems are treated without the benefit of having all options available, nor even known, and decision/actions are always taken within various constraints and limited resources: where choices are taken on a probabilistic ground. A pedagogical approach that aims at replacing such natural uncertainty with artificial determinism is one that negates the problems, often to the point of negating the negation itself (Stelleman, 1992). As Watzlawick puts it: "For he who sees behind the facade is damned if he sees and says that he sees, or crazy if he sees but does not even admit it to himself." (Watzlawick, Weakland, \& Fisch, 2011).

In an educational environment we need to consider, on top of all factors above, that our designers are students whose abilities and skills are built, by definition, along the process. This particular aspect of uncertainty in a PBL environment deserves special attention, as it is linked to the way we shape the learning environment around the students. A product is built together with others in an environment that offers resources: physical or technological, cognitive or collaborative tools, sources of information, social sources and related cases (Jonassen, 1999). At the outset, when working in the ideation or planning stage, students do not know all the potential resources that the environment may offer: that requires time, and resources in the learning environment change as the project goes as well. Again, an effective way for the students to identify and use the resources is by discovery: students get to know what they can source from the learning environment around them following the needs emerging in their problem-solving. The key-factor here is that what fuels the discovery process in the student is the need to know, the will to do something to resolve something else. When such will emerges it needs to be facilitated by giving the student access to the Internet, handbooks, books, papers, and-crucially-expert's advise: the flagship format of transmissive approaches, the lecture remains a precious resource if offered right when the need for it is built and clearly felt by the students in a PBL environment. In such context, the lecture becomes a very effective constructivist/constructionist learning tool.

It is in these kinds of processes, naturally permeated of uncertainty and constantly subjected to change, that Agile Project Management (APM) is meant to work. Again, importing in an educational environment APM approaches, such as "SCRUM" or "Extreme Planning" to name just the most popular (Beck, 2000; Schwaber, 2004; Sutherland, 2014), implies rethinking them at least to some degree; after all, an excessive bureaucratization of the process would be lethal for the student's ability to explore the learning environment and difficult to manage for teachers themselves. As far as this paper is concerned, our objective is to identify a few overarching principles on the ground of which the teaching model for 
"Building Beauty" is meant to develop and grow in the future; such principles are four, as illustrated below:

1) Incremental and iterative process. The project's process should be conceived as a series of cycles capable to address changes on the go, and progress towards the objective in an iterative and incremental way. As such, it is made of "adaptive cycles" distributed according to the different scales of the project, where by "scale" we mean both temporal and spatial. That is nothing unique to architecture or, indeed, education in general: it is in fact a general model of change that seems to apply to all complex systems in nature, society and culture (Friend \& Hickling, 2005; Gunderson \& Holling, 2002; Holling \& Goldberg, 1971).

2) User-orientated product. Even though conventional PM always includes a preliminary analysis of the user's needs to define the product, an APM approach suggests radically shifting the focus from the product to the user throughout all phases of the project. That means starting from a prototype that gets immediately tested, fine-tuned and documented for the benefit of the next cycle; in this testing exercise the user is continuously interrogated with regards to the prototype. For example, Alexander's activities of Land Exploration and Pattern Language clearly serve to explore the nature of the product at the early stage of ideation, which is the same position and purpose of conventional architectural "programming" (Preiser, 2015). However, the difference-indeed crucial-is that Alexander conducts the exploration at the profound level of users' shared human values and "dreams" (Porta, Russell, Romice, \& Vidoli, 2014).

3) Heuristic approach to knowledge. Students are encouraged to build their knowledge "by-themselves", where the teacher's task is to assist her/him in their own exploration of the learning environment rather than transmitting solutions. Such exploration always occurs within a condition of limited resources, of time, money, previous knowledge, and continuously tests and challenges such constraints. The solution, in a process of this kind, is always based on "what we know/can at the moment" and is, therefore, inherently transitional.

4) Closing to get started. In a project process made of cycles, at each cycle (or "sprint" in APM terminology (Schwaber, 2004), the moment of closure prepares and instructs the next cycle's moment of start. That must give to the closure an entirely different balance of activities, where the reflection side of things, i.e. the "retrospective", gains importance, and the communication part slips to the background.

\subsection{Summing it up: Building Beauty through Agile Project Management.}

One of the most innovative and important characteristics of "Building Beauty" is that education in architecture is pursued through constant immersion in a process of real, direct construction. Alexander has repetitively warned that no education in architecture can actually even start grasping the core of the subject without the continuous direct exposition of the student to the direct personal experience of making. Importantly, for Alexander the importance of this element in educating future architects is not due to the technical skills that would be generated-as important as they are-but rather to the emotional: it is only through the constant attention and restless effort that goes into "getting things just right" that students 
can understand the meaning of the order of space, the profound identity of which resonates in their own identity as human beings. Construction is, in Alexander, exactly that smooth process of trial and error, occurring in the reality of the building site, that governs living transformation in all domains of life, society and culture. An Agile Project Management approach to the teaching model is what guarantees consistency between what is taught and how it is taught, towards the acknowledgement that "wholeness" emerges through different areas of human action and nature seamlessly, like in this case unifying architecture and education under the same life-orientated principles. The way is long before we can claim to have understood how to put all this in practice, but it is an objective of the new program in Naples to explore and test ideas in both the areas.

\section{Conclusions.}

The paper illustrates a new educational program in architecture that is going to be launched in 2017 at the University Suor Orsola Benincasa in Naples. The program, named "Building Beauty: Experience of Ecologic Design and Construction Process", is international and radically innovative in terms of both contents and teaching model. Building on Christopher Alexander's principles as expressed in "The Nature of Order" (idem) as well as throughout his whole extraordinary intellectual production, the new program brings into the domain of architectural education various experiences that have not, historically, been considered part of it; in particular, students build for real with their own hands throughout the program, cultivate the land, and explore their individual and collective self; they are constantly immersed in an uninterrupted flow of real construction activities, which will constitute the heart and the environment for all other learning experiences in the program. The continuous contact with the exceptional beauty of the university venue, a $17^{\text {th }}$ century monastic complex situated in a panoramic position in the heart of the city of Naples, is of paramount importance and acts as a primary learning tool in the proposed curriculum. Finally, coherence between what is taught and how it is taught in the program, i.e. the architectural and pedagogical models, is actively sought through live scientific experimentation and the establishment of a distinct path of professional research entitled "The Objective Nature of Beauty". The ambition of the program is to contribute tackling the challenges of the age of urbanisation by proposing a radical change in architectural education and practice, based on " $21^{\text {st }}$ century skills". The proposed one-year Master is expected to be the first step towards the creation of a proper post-graduate degree or, further on, a full program in architecture and construction; challenges to the success of the initiative are, however, innumerable.

\section{References}

Abdullah, Z. B. (2014). Exploring the evolution of design-build courses in architectural schools: A qualitative study. The University of Nebraska-Lincoln.

Alexander, C. (1982). Lecture at Harvard Graduate School of Design [Transcription of audio recording].

Alexander, C. (2002a). The nature of order: an essay on the art of building and the nature of the universe. Book 1: The phenomenon of life. Berkeley, CA: Center for Environmental Structure.

Alexander, C. (2002b). Some sober reflections on the nature of architecture in our time. Rebuttal to William Saunders. Retrieved from The Nature of Order website: http://natureoforder.com/library/reply-to-saunders.htm 
Alexander, C. (2003). The nature of order: an essay on the art of building and the nature of the universe. Book 2: The process of creating life. Berkeley, CA: Center for Environmental Structure.

Alexander, C. (2004a) The Battle for Ordinary Human Existence in Our Time/Interviewer: K. O'Connell. Traditional Building.

Alexander, C. (2004b). The nature of order: an essay on the art of building and the nature of the universe. Book 4: The Iuminous ground. Berkeley, CA: Center for Environmental Structure.

Alexander, C. (2004c). Sustainability and morphogenesis: The birth of a living world. Paper presented at the Schumacher Lecture, Bristol, UK.

Alexander, C. (2004d). Sustainability and morphogenesis: The birth of a living world. Paper presented at the Schumacher Lecture, Bristol, UK.

Alexander, C. (2005). The nature of order: an essay on the art of building and the nature of the universe. Book 3: A vision of a living world. Berkeley, CA: Center for Environmental Structure.

Alexander, C. (2007). Summary of Empirical Findings from The Nature of Order. Environmental and Architectural Phenomenology, 18(1), 11-19.

Alexander, C. (2016). Making the Garden. First Things, February(260), 23-28.

Alexander, C., Davis, H., Martinez, J., \& Corner, D. (1985). The production of houses. New York: Oxford University Press.

Alexander, C., Neis, H., \& Moore-Alexander, M. (2012). The battle for the life and beauty of the earth : a struggle between two world-systems. New York: Oxford University Press.

Arter, J., \& McTighe, J. (2001). Scoring rubrics in the classroom: Using performance criteria for assessing and improving student performance: Corwin Press.

Barrows, H. S., \& Tamblyn, R. M. (1980). Problem-based learning: An approach to medical education: Springer Publishing Company.

Beck, K. (2000). Extreme programming explained: embrace change: Addison-Wesley Professional.

Beedle, M., van Bennekum, A., Cockburn, A., Cunningham, W., Fowler, M., Highsmith, J., . . . Thomas, D. (Producer). (2001). Manifesto for Agile Software Development. Retrieved from http://agilemanifesto.org

Bellanca, J. A. (2011). 21st century skills: Rethinking how students learn: Solution Tree Press.

Blumenfeld, P. C., Soloway, E., Marx, R. W., Krajcik, J. S., Guzdial, M., \& Palincsar, A. (1991). Motivating project-based learning: Sustaining the doing, supporting the learning. Educational psychologist, 26(3-4), 369-398.

Boano, C., \& Kelling, E. (2013). Toward an Architecture of Dissensus: Participatory Urbanism in South-East Asia. Footprint, 7(2), 41-62.

Boyer, E. L., \& Mitgang, L. D. (1996). Building Community: A New Future for Architecture Education and Practice. A Special Report: ERIC.

Brolin, B. C. (1976). The failure of modern architecture: Studio vista London.

Brown, J. B. (2012). A critique of the live project. Doctoral dissertation). Queen's University, Belfast.

Bruner, J. S. (1961). The act of discovery. Harvard educational review.

Bruner, J. S. (2009). The process of education: Harvard University Press.

Carpenter, W. J. (1997). Learning by building: Design and construction in architectural education: John Wiley \& Sons.

Colomina, B., Choi, E., Galan, I. G., \& Meister, A.-M. (2012). Radical pedagogies. Architectural Review, 232(1388), 78-82.

Farrell, T. (2014). The Farrell Review of Architecture and the Built Environment. London: London: Farrells Retrieved from http://www.farrellreview.co.uk.

Friend, J. K., \& Hickling, A. (2005). Planning under pressure: the strategic choice approach: Routledge.

Gardner, H. (1984). Frames of Mind: The Theory of Multiple Intelligences (pp. 440): William Heinemann Ltd. 
Gluck+ (Producer). (2013, 24/09/2016). Building Matters. [Video resource at: https://vimeo.com/60839567] Retrieved from https://vimeo.com/60839567

Gunderson, L. H., \& Holling, C. S. (Eds.). (2002). Panarchy: understanding transformations in human and natural systems. Washington D.C.: Island press.

Habraken, N. J., \& Teicher, J. (2000). The structure of the ordinary: form and control in the built environment: MIT press.

Hamdi, N. (2010). The Placemaker's Guide to Building Community: Earthscan.

Hayes, R. W. (2007). The Yale Building Project: The First 40 Years. New Haven: Yale University Press.

Highsmith, J. (2009). Agile project management: creating innovative products: Pearson Education.

Holling, C. S., \& Goldberg, M. A. (1971). Ecology and planning. Journal of the american Institute of Planners, 37(4), 221-230.

Jonassen, D. H. (1999). Designing constructivist learning environments. Instructional design theories and models: A new paradigm of instructional theory, 2, 215-239.

Kroll, L. (1986). The architecture of complexity: The MIT Press.

Martin, L. (1972). The Grid as a Generator. In L. Martin \& L. March (Eds.), Urban Space and Structures (pp. 6-27). Cambridge: University Press.

Morin, E. (2002). Seven complex lessons in education for the future: Unesco.

Ockman, J. (2012). Architecture school: three centuries of educating architects in North America: MIT Press.

P21 (Producer). (2002, September 2016). Partnership for 21st Century Learning. Retrieved from http://www.p21.org

Papert, S. (1987). Constructionism: A New Opportunity for Elementary Science Education. MIT, Boston MA: National Science Foundation.

Parvin, A. (Producer). (2013, 10/03/2016). Architecture for the people by the people. TED Talks. Retrieved from http://www.ted.com/talks/alastair_parvin_architecture_for_the_people_by_the_people

PMBoK, A. (2000). Guide to the project Management body of knowledge. Project Management Institute, Pennsylvania USA.

Popham, W. J. (1997). What's wrong-and what's right-with rubrics. Educational leadership, $55,72-75$.

Porta, S., Russell, P., Romice, O., \& Vidoli, M. (2014). Construction and Therapy: an Integrated Approach to Design Build. In T. Cavanagh, U. Hartig, \& S. Palleroni (Eds.), Working Out: Thinking While Building (pp. 98-108). Halifax, NS: ACSA Press.

Preiser, W. F. (2015). Programming the Built Environment (Routledge Revivals): Routledge.

Reeves, T. C., \& Hedberg, J. G. (2003). Interactive learning systems evaluation: Educational Technology.

RIBA, R. I. o. B. A.-. (2014). Skills Survey Report. Retrieved from London, UK:

Rittel, H. W., \& Webber, M. M. (1973). Dilemmas in a general theory of planning. Policy sciences, 4(2), 155-169.

Rudolfsky, B. (1972). Architecture Without Architects: A short introduction to non-pedigreed architecture: Academy Editions.

Salama, A. M. (2016). Spatial design education: New directions for pedagogy in architecture and beyond: Routledge.

Sanoff, H. (2000). Community participation methods in design and planning: John Wiley \& Sons.

Sara, R. (2006). Live Project Good Practice: a guide for the implementation of live projects: CEBE.

Schwaber, K. (2004). Agile project management with Scrum: Microsoft press.

Spiro, R. J., \& Jehng, J.-C. (1990). Cognitive flexibility and hypertext: Theory and technology for the nonlinear and multidimensional traversal of complex subject matter. Cognition, education, and multimedia: Exploring ideas in high technology, 205, 163-205.

Stelleman, J. (1992). Aspects of dramatic communication: action, non-action, interaction:(AP Čechov, A. Blok, D. Charms): Rodopi. 
Sutherland, J. (2014). Scrum: the art of doing twice the work in half the time: Crown Business.

Trechsel, G., \& Moos, D. (2003). Samuel Mockbee and the Rural Studio: Community Architecture: Birmingham Museum of Art.

Turner, J. F. (1977). Housing by people: Towards autonomy in building environments: Pantheon Books New York.

Turner, J. F., \& Fichter, R. (1972). Freedom to build: dweller control of the housing process: Macmillan.

Watzlawick, P., Weakland, J. H., \& Fisch, R. (2011). Change: Principles of problem formation and problem resolution: WW Norton \& Company.

Wittgenstein, L. (1953). Philosophical investigations. 1967. Oxford: Blackwell.

Wolfe, T. (1981). From Bauhaus to Our House: Farrar, Straus and Giroux.

Wright, A. (2013). Pathways and gateways: the structure and regulation of architectural education - Preliminary Report. Retrieved from http://www.schosa.org.uk/sites/all/files/Preliminary Report - Pathways and Gateways.pdf

Zecchi, E. (Producer). (2007). Lepida Scuola e il doppio ambiente di apprendimento, Strategie e tecnologie per la didattica.

Zecchi, E. (Producer). (2012). Project Based Learning (PBL) activities using the "Lepida Scuola" method.

\section{About the author/s:}

\section{Maggie Moore Alexander.}

Maggie Moore Alexander is President of the Center for Environmental Structure. She also serves as Christopher Alexander's editor, and has worked with him to produce The Nature of Order and The Battle for the Life and Beauty of the Earth: A Struggle Between Two WorldSystems, as well as other projects. She has a Masters Degree in Organization Change and Development.

\section{Enzo Zecchi.}

Enzo Zecchi, graduated cum laude in Theoretical Physics, author of PBL LepidaSchool method, is advisor of USR in Bologna; he collaborates with universities, foundations and institutes. He carried out research at the University of Parma, the Universite Scientifique et Medicale in Grenoble, the Fiat Research Centre in Turin, and the CEA (Commissariat a I'Energie Atomique) in France. He taught Systems Theory at the Inst. Pascal in Reggio Emilia, and Educational Technology at the University of Modena and Reggio. He is engaged in an intensive teacher training activity and is author of many publications.

\section{Peter Russell.}

Peter Russell was awarded a M.Arch from the University at Buffalo and an MSc from the University of Strathclyde. He currently is the Director of the Materials and Methods Lab at the University at Buffalo. Research areas include design-build pedagogy, public interest design, and the democratization of making in the built environment. Recent work includes developing a design build partnership in Buffalo to re-design and re-build existing structures into affordable housing that is universally designed. 


\section{Mariapia Vidoli.}

Mariapia Vidoli is PhD student at the Urban Design Studies Unit (UDSU) of University of Strathclyde in Glasgow. She graduated in Philosofy in Italy with a thesis on "The man in Ernest Cassirer. An active metahaphysics". Her research is about movement and therapy as applied to processes of live-build construction after Christopher Alexander, named "Costruction and Therapy".

\section{Antonio Caperna.}

Architect, graduated at the University Federico II in Naples, Antonio Caperna was awarded a PhD from Roma Tre University in Rome. Visiting Professor in several universities, he has taught at University of Rome "La Sapienza" and, since 2005, at Roma Tre. He's latest research is on the emergent field of Biourbanism and the application of complexity theory, evolutionary biology, Biophilia and Morphogenesis to define procedure/process and tools for a human-oriented architecture and urbanism. His latest work is a chapter in Smart Economy in Smart Cities (Springer Publishing).

\section{Ombretta Romice.}

Ombretta Romice (RTPI) is Senior Lecturer in Urban design at the Department of Architecture, University of Strathclyde, Glasgow and Fellow of the Higher Education Academy. She holds a PhD in urban design and a PostDoc in housing and regeneration sponsored by the European Union. She is member of the Urban Design Studies Unit (www.udsu-strath.com) where she teaches and researches in the areas of urban design, spatial planning, urban morphology, environmental psychology and user participation in design. She is past president of IAPS (International Association for People-Environment Studies).

\section{Sergio Porta.}

Sergio Porta, architect, is Professor of Urban Design and Director of the Urban Design Studies Unit (www.udsu-strath.com) at the Dept. of Architecture of the Univ. of Strathclyde in Glasgow, UK. His research is on Sustainable Urban Design, including masterplanning for adaptive urbanism, urban morphology and evolution, network analysis of urban spatial systems, community based construction process and beauty generation, construction and therapy. He has published over forty papers on international peer-reviewed journals and two monographs. He sits on the editorial boards of several leading journals of urban science and design and has been invited speaker at various international conferences including UNHabitat in Geneva and Barcelona, University of Cambridge, UCL London and the Venice Biennale. 